\title{
The persistence of precious metals and oil during the COVID-19 pandemic: evidence from a fractional integration and cointegration approach
}

\author{
Nuruddeen Usman ${ }^{1} \cdot$ Seyi Saint Akadiri ${ }^{2}$ \\ Received: 5 January 2021 / Accepted: 13 July 2021 / Published online: 14 August 2021 \\ (C) The Author(s), under exclusive licence to Springer-Verlag GmbH Germany, part of Springer Nature 2021
}

\begin{abstract}
In this paper, the behavior of precious metals and oil is examined using a fractionally integrated and cointegrated modeling approach. Using daily data from January 2015 to December 2020 and using both endogenous and exogenous structural breaks, we examine the behavior of the related series before and during the COVID-19 pandemic with the aim of investigating whether the degree of persistence has changed since the onset of COVID-19. We found that precious metals and oil exhibit long memory and are mean reverting regardless of the sample considered as the fractional parameter $d<0.5$. However, when structural breaks are taken into consideration, an increase in persistence is found during the COVID-19 as compared to the period before it. In addition, the fractionally cointegrated vector autoregressive (FCVAR) model of Johansen and Nielsen $(2010,2012)$ is used to examine the existence of long-run relationship among precious metals and oil price. We find the integrated parameters at $d<0.5$ for all samples except for the pre-COVID-19 sample. This highlights that the FCVAR is a better fit for the full sample and the COVID-19 and the COVID-19 pandemic period sub-samples, as the fractional parameter is $d<0.5$ while the CVAR model is better fit for the pre-COVID-19 period where $d>0.5$. Both cointegration techniques alongside the parameter stability tests lend support to the existence of a persistence and stable long-run relationships among the series irrespective of the sample period considered. Attendant policy recommendations for investors and policymakers are recommended.
\end{abstract}

Keywords Precious metals · Oil prices · Fractionally cointegration VAR $\cdot$ CVAR $\cdot$ COVID-19

\section{Introduction}

Initially, the COVID-19 pandemic emerged as a health epidemic in China, but the highly contagious virus quickly metamorphosed into an unparalleled global pandemic within 3 months. Governments employed aggressive steps to curb its spread. These include, among other measures, travel

Responsible Editor: Philippe Garrigues

Seyi Saint Akadiri ssakadiri@cbn.gov.ng

Nuruddeen Usman nusman2@cbn.gov.ng

1 Monetary Policy Department, Central Bank of Nigeria, Abuja, Nigeria

2 Research Department, Central Bank of Nigeria, Abuja, Nigeria restrictions and the complete lockdown of industries and companies across the globe. Economies have been impacted by these disturbances, arising primarily from supply chain disruptions, declining demand, and with attendant effects on the financial sector. While the real effect of the outbreak is yet to be quantified, the COVID-19 pandemic has created a new economy that has produced a large amount of data that will allow practitioners and scholars to validate whether established relationships that held in the past are still valid considering the increase uncertainty generated by the pandemic Salisu et al. (2020).

Precious metals have always been considered leading indicators of inflation and key variables that transmit the outlook for monetary policy in an economy (Greenspan 1993). Consequently, the pro-cyclical behavior of the price of precious metals has highlighted their functions as stores of value and safe heavens that provide critical information on the direction of an economy. In addition, Balcilar et al. (2021) and Balcilar and Usman (2021) emphasize that the important role oil price plays in formulating an optimal monetary policy 
especially in resource rich economies. The traditional view of precious metals is that they act as a haven against inflation and provide diversification benefits to investors during periods of high uncertainty ${ }^{1}$ (see Baur and Lucey 2010; Batten et al. 2010; Arouri et al. 2012; Gil-Alana et al. 2015a; Gil-Alana et al. 2015b). Thus, the motivation behind this study is to examine the behavior of precious metals and oil. This current study seeks to evaluate the persistence of the time series data under investigation. It is pertinent to state here that the persistence $^{2}$ feature in a time series data measures how short-term shocks lead to permanent future changes (Gil-Alana et al. 2013). Understanding the past developments in the behavior of precious metals and oil is critical to anticipate future price changes. ${ }^{3}$ The movements in the price of precious metal and oil have implications in gauging the trends of the whole commodity market (Bildirici and Turkmen 2015). Furthermore, precious metals and oil have become vital source of revenue for a lot of countries especially resource-rich economies. Consequently, examining the behavior during the COVID19 pandemic as compared to the period before it will help provide information on forecasting the respective series and their potential effects on commodity markets and world economic development. In addition, the persistence nature of a series may be transmitted to other macroeconomic indicators where the impact of shocks could be permanent or transitory.

Several papers have empirically examined the persistence of precious metals. Gil-Alana et al. (2015a) examine the persistence of five major precious metals (gold, silver, rhodium, palladium, and platinum) using a parametric and semiparametric fractional integration framework that considers structural breaks in the series. They find an increase in the degree of persistence of precious metals. Arouri et al. (2012) also use parametric and semi-parametric techniques while using the AFRIMA-FIGARCH model to examine if the returns of gold, silver, platinum, and palladium prices exhibit long memory and consequently find strong evidence of long memory. Using a similar technique as Arouri et al. (2012), Kirkulak and Lkhamazhapov (2014) find evidence of dual long memory in spot series and a lack of long memory characteristic in future returns.

The COVID-19 pandemic has brought attention to the behavior of financial markets (e.g., Corbet et al. 2020; Ashraf 2020; Phan and Narayan 2020; Akhtaruzzaman et al. 2021, 2020; Al-Awadhi et al. 2020; Mishra et al. 2020; Salisu and

\footnotetext{
${ }^{1}$ The financialization of commodities has exposed commodity prices to market-wide shock (see Cai et al. 2001; Tang and Xiong 2012).

${ }^{2}$ Persistence can be measured using traditional unit root tests (e.g., Phillips and Perron 1988); however, unit root tests have low power when the degree of persistence is high and consequently leads to over-accepting the null hypothesis Caporale and Pittis (1999). In addition, traditional unit root tests have low power when the series are characterized by a fractional process (Diebold and Rudebusch 1991; Robinson 1994; and Ben Nasr et al., 2014).

${ }^{3}$ The persistence of a series has implications for consumers, producers, policymakers, and portfolio managers.
}

Sikiru 2020; Salisu et al. 2020; Salisu and Vo 2020; Topcu and Gulal 2020; Zhang et al. 2020, among others). Salisu et al. (2020) and Salisu and Vo (2020) contend that the pandemic has increased the degree of uncertainty in financial markets. Ji et al. (2020) evaluate the haven properties of commodities, cryptocurrencies, foreign exchange, and gold against movements in equity prices finding soybean futures and gold remain robust as safe haven assets during the pandemic. Mensi et al. (2020) used an asymmetric multifractal detrended fluctuation approach and find that gold and oil markets have become inefficient during the pandemic and that the efficiency is sensitive to scales and market trends. Finally, GilAlana and Monge (2020) examine the persistence of oil price using a fractionally integrated approach in response to the COVID- $19^{4}$ pandemic. They find evidence of market efficiency prior to the crisis, with the oil market becoming inefficient when incorporating the data covering the crisis.

The goal of this paper is to examine the persistence of three major precious metals (gold, silver, and platinum) and oil using a fractional integration technique with the aim of investigating whether the degree of persistence has changed since the onset of COVID-19. We believe that studying the nature of the persistence of precious metals and oil prices at a time, where the world is facing the pandemic, would provide valuable information to investors, academic scholars, interested individuals, and most importantly the policymakers. If precious metals and oil exhibit long memory, this suggests that any shock will require a long horizon for the impact to dissipate, while the opposite holds for the case of short memory. Thus, an outcome of this paper will help specifically investors and policymakers to assess the risk associated with investment in precious metals and oil markets and possible strategies to take in presence of shocks, having understood the nature of the potential shocks facing these markets. ${ }^{5}$ Second, a test is carried out to determine whether precious metals and oil are fractionally cointegrated using the Fractionally Cointegrating VAR model proposed by Johansen and Nielsen (2012) using a time series daily frequency data between the periods 1 st January 2015 and 24th December 2020 for gold, silver, platinum, and oil price (Brent) respectively. The benefit of the fractionally cointegrated vector autoregressive (FCVAR) model is that it allows for the possibility of fractional integration when testing cointegration among relationships as compared to the traditional cointegrating vector autoregressive (CVAR) model of Johansen (1996).

The contribution of this study is of twofold: empirical and methodological. Methodologically, results obtained show that

\footnotetext{
${ }^{4}$ For more literature on oil price and the COVID-19 pandemic, see Narayan (2020), Devpura and Narayan (2020), Akhtaruzzaman et al. (2020a, b), and Mugaloglu et al. (2021).

${ }^{5}$ The nature of the shocks includes whether the series exhibits long or short memory and if the shocks to the series are transitory or permanent.
} 
the integrated parameters $(d<0.5)$ is less than 0.5 for all samples except for the pre-COVID-19 sample. Correspondingly, the LR statistics is significant for all samples with exception of the pre-COVID-19 sample. This highlights that the FCVAR is better fit for the full sample and the COVID-19 and the COVID-19 pandemic period sub-samples, as the fractional parameter is $d<0.5$ while the CVAR model is better fit for the pre-COVID-19 period where $d>0.5$. Both cointegration techniques alongside the parameter stability tests lend support to the existence of a persistence and stable long-run relationships among the series irrespective of the sample period considered. Empirically, we found a direct relationship between precious metals and oil prices; thus, precious metals respond and are sensitive to shocks to oil prices irrespective of the economic situations.

This study is organized as follows: "Introduction" presents the introduction, followed by research methodology in "Methodology." "Data and preliminary analyses" presents and discusses the descriptive and empirical results, while "Conclusion and policy implications" concludes the study with attendant policy suggestions.

\section{Methodology}

The study applies a fractional integration technique, which suggests that the number of differences required to make a series stationary $I(0)$ may be by order in a fractional form and may not necessarily take an integer value. Consequently, given a time series $x_{t} t=1,2$, the fractionally integrated model can be specified as follows:

$$
(1-L)^{d} x_{t}=\alpha+\gamma \text { Trend }+\varepsilon_{t} ;
$$

$d$ is any real value, and $\mathrm{L}$ is the lag operator $\left(L x_{t}=x\right) \cdot x_{t}$ is the $\log$ return of the series in question that is integrated of order $d$ and is represented by $x_{t} \approx I(d)$ and $\varepsilon_{t} \sim N\left(0, \sigma_{\varepsilon}^{2}\right.$.

For all real $d$, premised on its binomial expansion, the polynomial $(1-L)^{d}$ in Eq. (1) can be presented as follows:

$$
\begin{aligned}
(1-L)^{d} & =\sum_{j=0}^{\infty} \phi_{j} L^{j}=\sum_{j=0}^{\infty}\left(\begin{array}{c}
d \\
j
\end{array}\right)(-1)^{j} L^{j} \\
& =1-d L+\frac{d(d-1)}{2} L^{2}-\ldots,
\end{aligned}
$$

therefore,

$(1-L)^{d} \pi_{t}=x_{t}-d x_{t-1}+\frac{d(d-1)}{2} x_{t-2}-\ldots$

Hence, Eq. (1) can be presented as follows:

$x_{t}=\alpha+\gamma$ Trend $+d x_{t-1}+\frac{d(d-1)}{2} Z_{t-2}-\ldots+\varepsilon_{t}$
Equation (4) is built to underscore the key role $d$ also plays in the calculation of the degree of persistence in the series as it describes the amount of dependence of the series (Gil-Alana and Carcel 2020). Consequently, the higher the value $d$, the higher will be the level of dependence between observations in the series and consequently a higher degree of persistence.

Based on the specification in Eq. (4), three results are possible depending on the value of $d$. Firstly, if $d=0$, then $x_{t}$ displays low-level persistence (i.e., "short memory") and the autocorrelations decay in an exponentially fast manner with the series being termed $I(0)$ or covariance stationary and validates the efficient market hypothesis (EMH). Secondly, if $d$ falls within the range of $(0,0.5)$, then $x_{t}$ is termed as long memory due to the high degree of associations between observations that are distant in time. However, this process is stationary and mean reverting. Thirdly, if $d \geq 0.5$, then $x_{t}$ is presumed to be non-stationary but mean reverting, and the EMH does not hold. In the long memory scenario, $x_{t}$ can exhibit properties of mean or non-mean reversion processes based on the value of $d$. If $0.5<d<1$, then $x_{t}$ is mean reverting, and any policy will have a temporary influence on the series. Finally, if $d \geq 1$, then $x_{t}$ is non-mean reverting, and any policy shock on the series will have a permanent effect on the series. The parametric method Sowell (1992), which involves a maximum likelihood estimator, is used for estimating the fractional differencing parameter $d .^{6}$

In addition, using the FCVAR model of Johansen and Nielsen $(2010,2012)$, the long-run properties of precious metals and oil are considered in a multivariate setting. The FCVAR allows for a fractional process of order $d$ that cointegrates to order $d-b$. The model is a constructed based on Johansen's (1995) CVAR model. From a policy viewpoint, if precious metals and oil prices are cointegrated, this will be that, any policy action aimed at a specific variable will also influence other series. Additionally, if the cointegration is fractional, the impact of policy on these variables will only disperse after long horizons. Using the CVAR model as baseline, suppose that $x_{t}$ is a vector of $I(1)$ time series of element $p$, the error correction form of the CVAR model is presented as follows:

$$
\begin{aligned}
\Delta x_{t} & =\alpha \beta^{\prime} \mathrm{x}_{t-1}+\sum_{i=1}^{k} \Gamma_{i} \Delta x_{t-i}+\varepsilon_{i} \\
& =\alpha \beta^{\prime} L x_{t}+\sum_{i=1}^{k} \Gamma_{i} \Delta L^{i} x_{t}+\varepsilon_{t}
\end{aligned}
$$

The FCVAR being a derivative of the CVAR is arrived at by interchanging the $\Delta$ and $L$ in Eq. (5) with their fractional equivalents in Eq. (6):

$\Delta^{d} Z_{t}=\alpha \beta^{\prime} \Delta^{d-b} L_{b} Z_{t}+\sum_{i=1}^{k} \Gamma_{i} \Delta^{d} L_{b}^{i} Z_{t}+\varepsilon_{t}$,

\footnotetext{
${ }^{6}$ For more detailed analyses of the different methods used to analyze fractional integration, see Robinson (1994) and Robinson (1995).
} 
given that $\Delta^{d}$ is the term indicating fractional difference and $L_{b}=1-\Delta^{b}$ is the fractional lag operator. $\alpha$ and $\beta$ are the long-run parameters that are the most relevant for the study and are $p \times r$ matrices with $0 \leq r \leq p$. The rank $r$ is the cofractional rank. Columns of $\beta$ comprise the $r$ co-fractional vectors, and $\beta^{\prime} x_{t}$ are the cointegrating combinations. $\alpha$ represents the speed of adjustment towards equilibrium for each of the variables. $\Gamma=\left(\Gamma_{1}, \ldots, \Gamma_{k}\right)$ captures the short-run dynamics of the variables in the autoregressive augmentation (Nielsen and Popiel 2018). ${ }^{7}$ Given that CVAR is a distinct case of the FCVAR, the FCVAR model condenses to the CVAR variant if $d=b=1$.

\section{Data and preliminary analyses}

The time series data used for analysis in this paper is of daily structure from 1st January 2015 to 24th December 2020 for gold, silver, platinum, and oil price (Brent). The data was sourced from Bloomberg. The results of the unit root test indicate that all the series are non-stationary. ${ }^{8}$ Table 1 contains the descriptive statistics for the data of the study. The full sample was split into the period before the occurrence of COVID-19 and after wave 1 of the occurrence of the pandemic. ${ }^{9}$ In addition to the exogenously determined breaks in the data, the presence of an endogenous structural break in the data is tested using the multivariate framework of Bai et al. (1998). ${ }^{10}$ A common break date in March 2020 is observed. ${ }^{11}$

As revealed in Table 1, gold, silver, and platinum recorded higher mean values for the period during COVID-19 as compared to oil where it recorded lower mean values. In addition, the three categories of precious metals and oil were more volatile in the COVID-19 sample than in the preCOVID-19 sample as can be seen from the higher standard deviation in the data. Following the descriptive analysis, Figure 1 reveals the graphical plots of the precious metals and oil prices with their returns respectively.

\footnotetext{
${ }^{7}$ The Matlab program of Nielsen and Popiel is used for estimation of FCVAR and CVAR models.

${ }^{8}$ Using standard unit root tests, such as the augmented Dickey and Fuller (1979) and Phillips and Perron (1988), we fail to reject the null hypothesis, i.e., the series has a unit root. This is in addition to the newly developed unit root tests of Narayan and Liu (2015), which allow for two structural breaks and arrive at a similar conclusion. (The results are available upon request.)

${ }^{9}$ See https://www.who.int/news/item/27-04-2020-who-timeline\%2D\%2Dcovid-19 for the timeline.

${ }^{10}$ The results are not reported here due to space constraint; however, they are available on request.

${ }^{11}$ This coincides with the period the World Health Organization (WHO) declared COVID-19 a pandemic.
}

Table 1 Descriptive statistics

\begin{tabular}{|c|c|c|c|c|}
\hline Statistics & Gold & Silver & Platinum & Oil \\
\hline \multicolumn{5}{|l|}{ Full sample } \\
\hline Mean & 1348.95 & 17.0345 & 937.0365 & 55.4057 \\
\hline Median & 1280.98 & 16.585 & 931.625 & 55.335 \\
\hline Maximum & 2063.54 & 29.1295 & 1285.13 & 86.29 \\
\hline Minimum & 1051.1 & 11.981 & 591.2 & 19.33 \\
\hline Std. Dev. & 215.603 & 2.64903 & 104.477 & 12.3065 \\
\hline Skewness & 1.42427 & 2.07802 & 0.628174 & -0.10177 \\
\hline Kurtosis & 4.25183 & 7.8556 & 3.646443 & 2.67986 \\
\hline Observation & 1558 & 1558 & 1558 & 1558 \\
\hline \multicolumn{5}{|c|}{ Pre-COVID-19 } \\
\hline Mean & 1265.71 & 16.3598 & 947.6298 & 57.8275 \\
\hline Median & 1262.38 & 16.4359 & 936.43 & 57.395 \\
\hline Maximum & 1552.55 & 20.6225 & 1285.13 & 86.29 \\
\hline Minimum & 1051.1 & 13.6759 & 768.66 & 27.88 \\
\hline Std. Dev. & 99.1719 & 1.36941 & 103.6331 & 11.1558 \\
\hline Skewness & 0.54118 & 0.40804 & 0.789038 & -0.02409 \\
\hline Kurtosis & 3.52302 & 3.0721 & 3.408142 & 2.6195 \\
\hline Observation & 1300 & 1300 & 1300 & 1300 \\
\hline \multicolumn{5}{|l|}{ COVID-19 } \\
\hline Mean & 1768.42 & 20.4344 & 883.6592 & 43.203 \\
\hline Median & 1770.69 & 18.2727 & 884.795 & 43.01 \\
\hline Maximum & 2063.54 & 29.1295 & 1060.62 & 68.91 \\
\hline Minimum & 1471.24 & 11.981 & 591.2 & 19.33 \\
\hline Std. Dev. & 142.199 & 4.37359 & 91.74845 & 12.4563 \\
\hline Skewness & -0.14609 & 0.1778 & -0.426801 & 0.17961 \\
\hline Kurtosis & 1.86622 & 1.67977 & 2.806567 & 3.07569 \\
\hline Observation & 258 & 258 & 258 & 258 \\
\hline \multicolumn{5}{|c|}{ COVID-19 pandemic } \\
\hline Mean & 1813.56 & 21.0846 & 894.6635 & 39.5397 \\
\hline Median & 1837.86 & 23.1475 & 866.57 & 41.92 \\
\hline Maximum & 2063.54 & 29.1295 & 1060.62 & 52.26 \\
\hline Minimum & 1471.24 & 11.981 & 591.2 & 19.33 \\
\hline Std. Dev. & 120.261 & 4.65536 & 90.51164 & 7.458 \\
\hline Skewness & -0.48529 & -0.19013 & -0.188123 & -0.88346 \\
\hline Kurtosis & 2.72192 & 1.59274 & 2.944228 & 3.05587 \\
\hline Observation & 207 & 207 & 207 & 207 \\
\hline
\end{tabular}

\section{Results}

\section{Are precious metals and oil fractionally integrated?}

For the EMH of Fama (1965) to hold, the series must be integrated of order zero (i.e., $d=0$ ) and consequently follow a random walk process. However, for the strong form of EMH to be violated, it requires that the fractional integrated parameter ranges within $(0,0.5)$, where the series exhibits long memory (stationary) and shocks to the series dies out within a short 
Gold

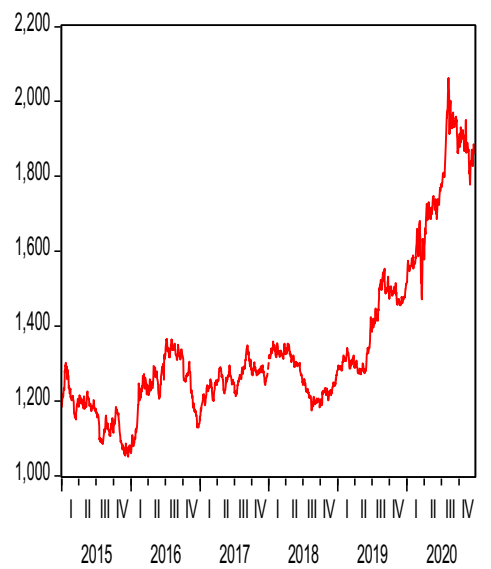

Oil Retruns

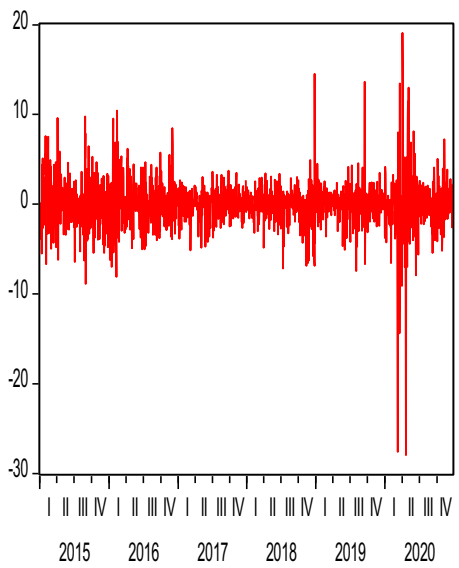

Silver

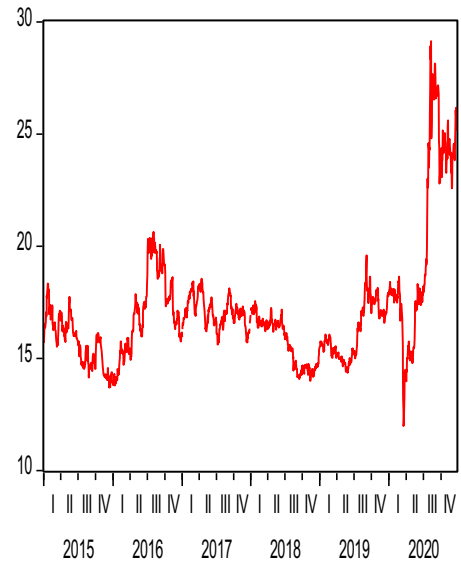

Gold Returns

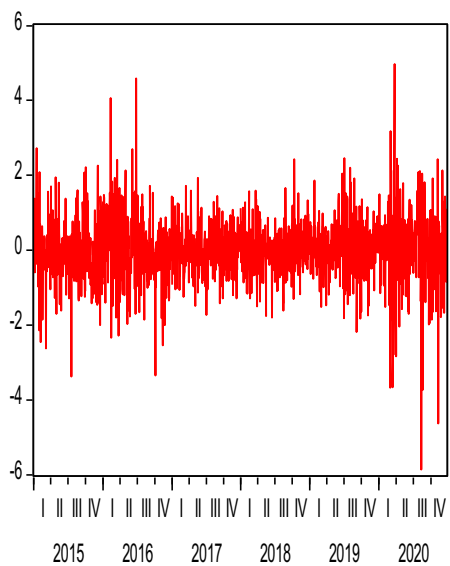

Platinum

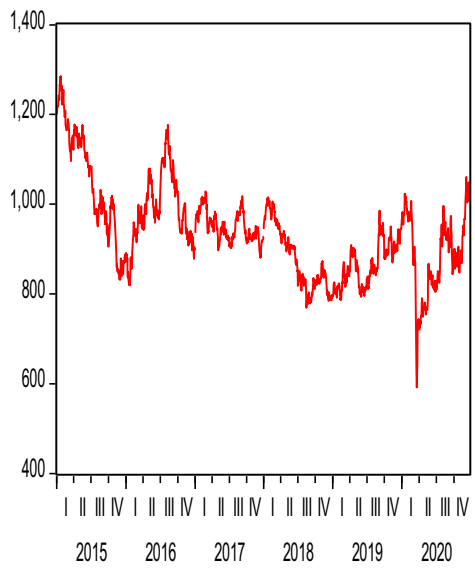

Silver Retruns

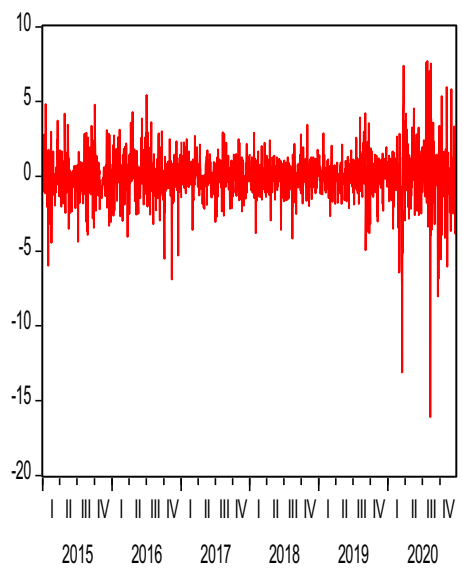

Oil

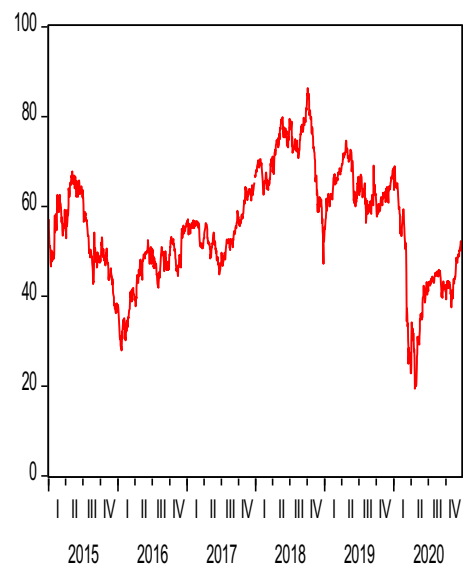

Platinum Returns

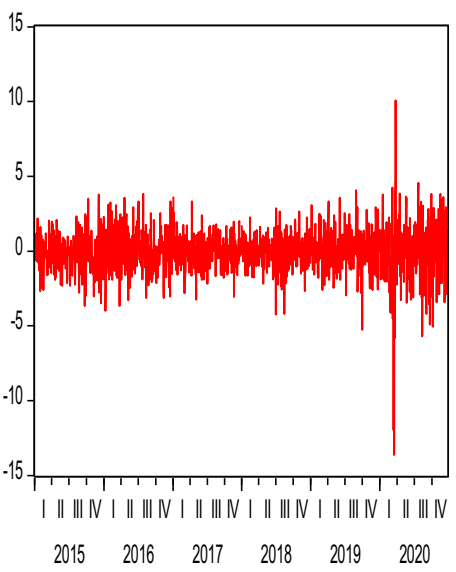

Fig. 1 Price and returns for gold, silver, platinum, and oil. Returns are computed as $\ln ^{\frac{x_{t}}{-}} x_{t-1} * 100$.

time frame for the weak form of EMH to hold. In the other scenario when the fractional parameter lies within the range of $0.5<d<1$ where the series exhibits long memory (nonstationary) with mean reversion, market inefficiency holds with the impact of shocks taking a long period to fizzle out, provided that the level of persistence is not permanent $d \geq 1$.
Table 2 presents the results of the fractionally integrated approach for the full sample under two scenarios: (i) an intercept and (ii) an intercept with a linear time trend. The results indicate the presence of long memory in the data as estimates of $d$ lie within the $(0,0.5)$ range and validate the presence of weak form efficient market hypothesis in the precious metals 
Table 2 Estimates of $d$ using the full sample

\begin{tabular}{|c|c|c|c|}
\hline \multicolumn{4}{|c|}{ Full sample } \\
\hline & & Intercept & Intercept \& trenc \\
\hline \multirow[t]{4}{*}{ Gold } & $d$ & $0.0029^{\text {**** }}$ & 0.0031 \\
\hline & & $(0.0031)$ & $(0.0031)$ \\
\hline & $d=1.0$ & $-56.7530^{* * * *}$ & $-56.3460^{* * * *}$ \\
\hline & & {$[0.0000]$} & {$[0.0000]$} \\
\hline \multirow[t]{4}{*}{ Silver } & $d$ & $0.0319^{* * * * *}$ & $0.0302^{* * * * *}$ \\
\hline & & $(0.0097)$ & $(0.0097)$ \\
\hline & $d=1.0$ & $-99.1614^{* * *}$ & $-99.2937^{* * * *}$ \\
\hline & & {$[0.0000]$} & {$[0.0000]$} \\
\hline \multirow[t]{4}{*}{ Platinum } & $d$ & $0.0397^{* * * *}$ & $0.0378^{\text {***** }}$ \\
\hline & & $(0.0129)$ & $(0.0128)$ \\
\hline & $d=1.0$ & $-74.4317^{* * * *}$ & $-74.837^{* * * *}$ \\
\hline & & {$[0.0000]$} & {$[0.0000]$} \\
\hline \multirow[t]{4}{*}{ Oil } & $d$ & $0.0106^{* * * *}$ & $0.0106^{* * * *}$ \\
\hline & & $(0.0018)$ & $(0.0001)$ \\
\hline & $d=1.0$ & $-101.2426^{* * *}$ & $-97.5951^{* * * *}$ \\
\hline & & {$[0.0000]$} & {$[0.0000]$} \\
\hline
\end{tabular}

Note: Values in square brackets are standard errors of the associated $d$ coefficients. ${ }^{* * * *},{ }^{* * *},{ }^{*}$ represent $1 \%, 5 \%$, and $10 \%$ levels of significance, respectively

and oil markets. In addition, to strengthen the analysis, a Wald test is performed to check if $d \geq 1$. The results reveal that although precious metals and oil exhibit long memory, any shock to the series will have a transitory effect (shocks disappearing in the long run) with mean reversion.

\section{Has COVID-19 changed the persistence of precious metals and oil?}

Following the segmentation of data periods before the emergence of COVID-19, during COVID-19, and when COVID19 was more pronounced as a pandemic (wave 1), an examination was carried out to see if the findings using the full sample were not biased by the option of sample periods used.

In a comparable routine to the full sample approach earlier, the persistence of the returns of precious metals and oil markets are examined using the fractionally integrated approach with an intercept and with intercept and a linear time trend in Table 3.

As with the full sample, precious metal and oil returns are found to be stationary and exhibiting long memory and mean reversion characteristics. However, of particular interest is how the degree of persistence has been increasing during the COVID-19 pandemic compared to the period before it. This could be attributed to an increase in uncertainty in financial markets because of the pandemic. As before, a Wald test was conducted to check if shocks to series are transitionary or permanent. It was found that the impact that is similar across samples is temporary, fading over long horizons.

\section{Are precious metals and oil fractionally cointegrated?}

Having confirmed that precious metals and oil are fractionally integrated and exhibit long memory, the FCVAR model of Johansen and Nielsen $(2010,2012)$ was used to examine if cointegrating relationships are better formed in a fractional setting or using the conventional CVAR of Johansen (1995). To do this, the integrated parameter and corresponding Likelihood Ratio (LR) Static were checked to corroborate whether long-run relationships are better formed in the FCVAR than the CVAR. As a prelude, the optimal lag is determined under two scenarios: (i) a model with deterministic trend and (ii) a model without a deterministic trend with the maximum lag set at 5 .

Table 3 Estimates $d$ using sub-samples

\begin{tabular}{|c|c|c|c|c|c|c|c|}
\hline & & Pre-COVID- & & COVID-19 & & COVID-19 F & mic \\
\hline \multirow{5}{*}{ Gold } & \multirow{3}{*}{$d$} & Intercept & Intercept \& trend & Intercept & Intercept \& trend & Intercept & Intercept \& trend \\
\hline & & $0.0015^{* * * * *}$ & $0.0016^{* * * *}$ & $0.0065^{* * * * *}$ & $0.0062^{* * * *}$ & $0.0072^{* * * *}$ & $0.0075^{* * * *}$ \\
\hline & & $(0.0009)$ & $(0.0009)$ & $(0.0021)$ & $(0.002)$ & $(0.0053)$ & $(0.0054)$ \\
\hline & \multirow[t]{2}{*}{$d=1.0$} & $-47.6676^{* * * *}$ & $-47.6881^{* * * *}$ & $-21.0166^{* * * *}$ & $-21.5646^{* * * *}$ & $-18.477^{* * * *}$ & $-18.4001^{* * * *}$ \\
\hline & & {$[0.0000]$} & {$[0.0000]$} & {$[0.0000]$} & {$[0.0000]$} & {$[0.0000]$} & {$[0.0000]$} \\
\hline \multirow[t]{4}{*}{ Silver } & \multirow[t]{2}{*}{$d$} & $0.0027^{* *}$ & $0.0025^{* *}$ & $0.0567^{*}$ & $0.0545^{*}$ & $0.0574^{*}$ & $0.0583^{*}$ \\
\hline & & $(0.0019)$ & $(0.0019)$ & $(0.0310)$ & $(0.0340)$ & $(0.0306)$ & $(0.0472)$ \\
\hline & \multirow[t]{2}{*}{$d=1.0$} & $-51.7725^{* * *}$ & $-51.7849^{* * * *}$ & $-30.3917^{* * * *}$ & $-27.7462^{* * * *}$ & $-25.755^{* * * *}$ & $-22.8492^{* * * *}$ \\
\hline & & {$[0.0000]$} & {$[0.0000]$} & {$[0.0000]$} & {$[0.0000]$} & {$[0.0000]$} & {$[0.0000]$} \\
\hline \multirow[t]{4}{*}{ Platinum } & \multirow[t]{2}{*}{$d$} & $0.0157^{* * *}$ & $0.0132^{* *}$ & $0.0692^{*}$ & $0.0599^{*}$ & $0.0934^{* * *}$ & $0.0901^{* * *}$ \\
\hline & & $(0.0020)$ & $(0.2010)$ & $(0.0396)$ & $(0.0413)$ & $(0.0443)$ & $(0.0472)$ \\
\hline & \multirow[t]{2}{*}{$d=1.0$} & $-49.0047^{* * * *}$ & $-49.0866^{* * *}$ & $-23.4825^{* * * *}$ & $-22.7173^{* * * *}$ & $-20.4577^{\text {**** }}$ & $-19.264^{* * * *}$ \\
\hline & & {$[0.0000]$} & {$[0.0000]$} & {$[0.0000]$} & {$[0.0000]$} & {$[0.0000]$} & {$[0.0000]$} \\
\hline \multirow[t]{4}{*}{ Oil } & \multirow[t]{2}{*}{$d$} & $0.0568^{* * * * *}$ & $0.0572^{* * * * *}$ & $0.0928^{* * * * *}$ & $0.0771^{* * * * *}$ & $0.0764^{* * *}$ & $0.0749^{* * * 3}$ \\
\hline & & $(0.0146)$ & $(0.0101)$ & $(0.0282)$ & $(0.0292)$ & $(0.0341)$ & $(0.0341)$ \\
\hline & \multirow[t]{2}{*}{$d=1.0$} & $-72.1797^{* * * *}$ & $-71.579^{* * * *}$ & $-32.1469^{* * * *}$ & $-31.580^{* * * *}$ & $-27.069^{* * * *}$ & $-27.059^{* * * *}$ \\
\hline & & {$[0.0000]$} & {$[0.0000]$} & {$[0.0000]$} & {$[0.0000]$} & {$[0.0000]$} & {$[0.0000]$} \\
\hline
\end{tabular}

Note: Values in parentheses are standard errors of the associated $d$ coefficients, while values in the square brackets are the $p$-values. ${ }^{* * *},{ }^{* *},{ }^{*}$ represent $1 \%, 5 \%$, and $10 \%$ levels of significance, respectively 
Table 4 Lag selection results for FCVAR model

\begin{tabular}{|c|c|c|c|c|c|c|c|c|}
\hline \multirow[t]{2}{*}{ K } & \multicolumn{2}{|c|}{ Full sample } & \multicolumn{2}{|c|}{ Pre-Covid19 } & \multicolumn{2}{|c|}{ COVID-19 } & \multicolumn{2}{|c|}{ COVID-19 pandemic } \\
\hline & AIC & $\mathrm{BIC}$ & AIC & $\mathrm{BIC}$ & AIC & $\mathrm{BIC}$ & AIC & $\mathrm{BIC}$ \\
\hline \multicolumn{9}{|c|}{ Excluding deterministic trend } \\
\hline 3 & 20429.96 & 20799.19 & 15224.34 & 15581.08 & $4285.58^{*}$ & 4530.74 & 3501.99 & 3731.95 \\
\hline 2 & $20429.14^{*}$ & 20712.75 & 15219.35 & 15493.36 & 4292.82 & 4481.13 & 3502.76 & 3679.39 \\
\hline 1 & 20443.79 & 20641.78 & 15226.95 & 15418.25 & 4295.55 & 4427.01 & 3498.33 & 3621.64 \\
\hline 0 & 20438.75 & $20551.13^{*}$ & $15218.37^{*}$ & $15326.94^{*}$ & 4299.09 & $4373.70^{*}$ & $3494.22 *$ & $3584.20^{*}$ \\
\hline \multicolumn{9}{|c|}{ Including deterministic trend } \\
\hline 3 & $20405.79^{*}$ & 20796.42 & $15220.94^{*}$ & 15598.36 & $4288.52^{*}$ & 4574.89 & 3470.84 & 3714.13 \\
\hline 2 & 20419.69 & 20724.71 & 15221.65 & 15516.34 & 4298.09 & 4500.61 & $3452.66^{*}$ & 3642.62 \\
\hline 1 & 20435.33 & 20654.73 & 15224.93 & 15436.97 & 4302.47 & 4448.15 & 3481.22 & 3617.86 \\
\hline 0 & 20444.73 & $20578.51^{*}$ & 15223.03 & $15352.28^{*}$ & 4302.85 & $4391.68^{*}$ & 3491.31 & $3574.62^{*}$ \\
\hline
\end{tabular}

Note: AIC represents the Akaike Information Criterion and BIC represents the Bayesian information criterion. The AIC is used in deciding the optimal lag
The optimum lag was selected based on the Akaike information criterion (AIC) across the full sample and the remaining sub-samples as reported in Table 4. For the models excluding a deterministic trend, the AIC picks a lag of 2, 0, 3, and 0 for the full sample and the pre-COVID-19, COVID-19, and COVID-19 pandemic sub-samples, respectively. For the model including a deterministic trend, the AIC selects lags of $3,3,3$, and 2 for the full sample and the pre-COVID-19, COVID-19, and COVID-19 pandemic sub-samples, respectively. The corresponding cointegration results are presented in Table 5. At different levels of significance for the model excluding deterministic trends, the null of no cointegration is rejected, for one cointegrating vector of the full sample and other sub-samples, respectively. For the model including a deterministic trend, the null of no cointegrating vectors for a maximum of 1, 2, 2, and $1 \operatorname{lag}(\mathrm{s})$ for the full sample and the pre-COVID-19, COVID-19, and COVID-19 pandemic subsamples, respectively. Consequently, this shows that precious metals and oil price returns are cointegrated irrespective of the sample period considered.

Table 6 presents the option between either the FCVAR or the conventional CVAR. The results obtained show the integrated parameters at $d<0.5$ for all samples except for the preCOVID-19 sample. Correspondingly, the LR statistics are significant for all samples with exception of the pre-COVID19 sample. This highlights that the cointegrating relationships are better fit, using the fractional integration framework for the full sample and the COVID-19 and the COVID-19 pandemic

Table 5 Cointegrating rank

\begin{tabular}{|c|c|c|c|c|c|c|c|c|c|c|c|c|}
\hline \multirow[t]{2}{*}{ Rank } & \multicolumn{3}{|c|}{ Full sample } & \multicolumn{3}{|c|}{ Pre-COVID-19 } & \multicolumn{3}{|c|}{ COVID-19 } & \multicolumn{3}{|c|}{ COVID-19 pandemic } \\
\hline & $d$ & $L R$ & $P$-value & $d$ & $L R$ & $P$-value & $d$ & $L R$ & $P$-value & $d$ & $L R$ & $P$-value \\
\hline \multicolumn{13}{|c|}{ Excluding deterministic trend } \\
\hline 0 & 0.010 & 47.186 & 0.000 & 0.010 & 39.686 & 0.000 & 0.136 & 39.982 & 0.001 & 0.010 & 50.361 & 0.052 \\
\hline 1 & 0.010 & 17.938 & 0.036 & 0.010 & 19.298 & 0.020 & 0.458 & 23.861 & 0.005 & 0.010 & 17.781 & 0.081 \\
\hline 2 & 0.101 & 6.761 & 0.149 & 0.010 & 2.633 & 0.621 & 0.478 & 4.067 & 0.397 & 0.057 & 4.005 & 0.405 \\
\hline 3 & 0.010 & 2.173 & 0.140 & 0.010 & 1.064 & 0.302 & 0.519 & 0.065 & - & 0.108 & 1.295 & 0.255 \\
\hline 4 & 0.391 & - & - & 0.010 & - & - & 0.509 & - & - & 0.563 & - & - \\
\hline \multicolumn{13}{|c|}{ Including deterministic trend } \\
\hline 0 & 0.101 & 54.794 & 0.000 & 0.010 & 31.271 & 0.000 & 0.071 & 38.711 & 0.001 & 0.010 & 59.458 & 0.000 \\
\hline 1 & 0.100 & 36.974 & 0.025 & 0.010 & 11.768 & 0.052 & 0.010 & 18.389 & 0.046 & 0.124 & 17.373 & 0.082 \\
\hline 2 & 0.010 & 5.447 & 0.153 & 0.010 & 10.717 & 0.083 & 0.176 & 13.506 & 0.083 & 0.093 & 8.129 & 0.173 \\
\hline 3 & 0.010 & 2.584 & 0.151 & 0.010 & 7.107 & 0.129 & 0.010 & 8.704 & 0.113 & 0.205 & 0.673 & 0.436 \\
\hline 4 & 0.479 & - & - & 0.010 & - & - & 0.538 & - & - & 0.203 & - & - \\
\hline
\end{tabular}

Note: $d$ represents the fractional parameter; the Likelihood Ratio is signified by $L R$ 
Table 6 Comparing the FCVAR with the CVAR

\begin{tabular}{|c|c|c|c|c|}
\hline \multirow[t]{2}{*}{ Period } & \multicolumn{2}{|c|}{ Excluding deterministic trend } & \multicolumn{2}{|c|}{ Including deterministic trend } \\
\hline & $d$ & $L R$ & $d$ & $L R$ \\
\hline Full sample & $0.010(0.000)$ & $768.935[0.000]$ & $0.010(0.000)$ & $292.401[0.000]$ \\
\hline Pre-COVID-19 & $1.282(0.013)$ & $2.687[0.174]$ & $1.286(0.012)$ & $1.896[0.164]$ \\
\hline COVID-19 & $0.010(0.041)$ & $120.24[0.000]$ & $0.010(0.000)$ & $53.073[0.000]$ \\
\hline COVID-19 pandemic & $0.010(0.031)$ & $549.937[0.000]$ & $0.093(0.020)$ & $112.238[0.000]$ \\
\hline
\end{tabular}

Note: $d$ represents the fractional parameter; the Likelihood Ratio is signified by $L R$

Fig. 2 Full sample stability test

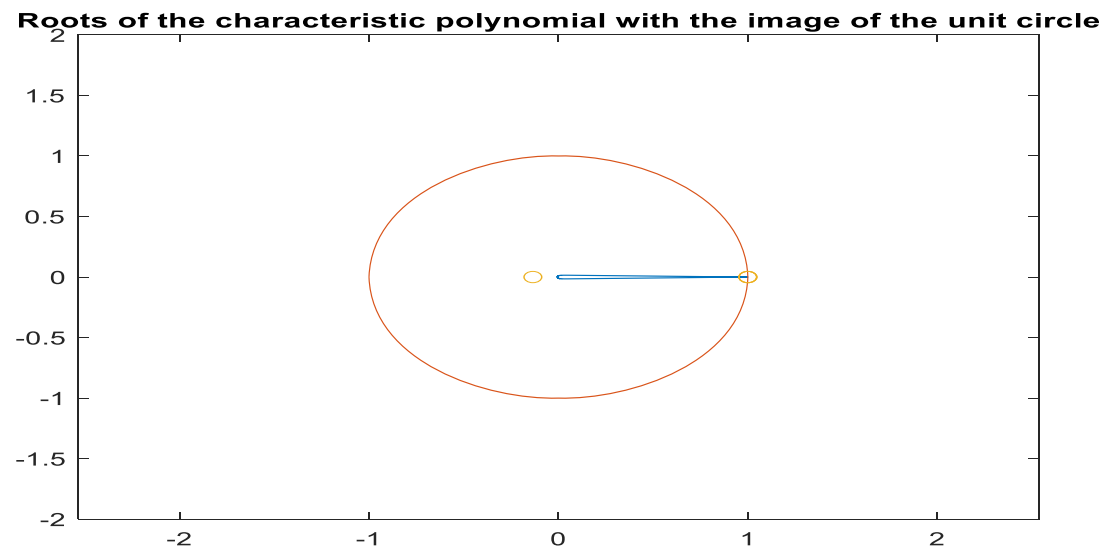

period sub-samples, as the fractional parameter is $d<0.5$ while the CVAR model is better fit for the pre-COVID-19 period where $d>0.5$. To check for parameter stability, the roots of the characteristic polynomial are presented in Figs. $2,3,4$, and 5 , which clearly lend credence to the validity of the results, as it confirms that the parameters are stable.

\section{Conclusion and policy implications}

The behavior of precious metals and oil is examined using a fractionally integrated and cointegrated modeling approach.
Using daily data from January 2015 to December 2020 and using both endogenous and exogenous structural breaks, it is found that precious metals and oil exhibit long memory and are mean reverting regardless of the sample considered as the fractional parameter $d<0.5$. However, when structural breaks are taken into consideration, an increase in persistence is found during the COVID-19 as compared to the period before it. In addition, using the FCVAR model as advanced by Johansen and Nielsen $(2010,2012)$ to examine the existence of long-run relationship among precious metals and oil price. we find the integrated parameters at $d<0.5$ for all samples except for the pre-COVID-19 sample. Correspondingly, the
Fig. 3 Pre-COVID-19 sample stability test

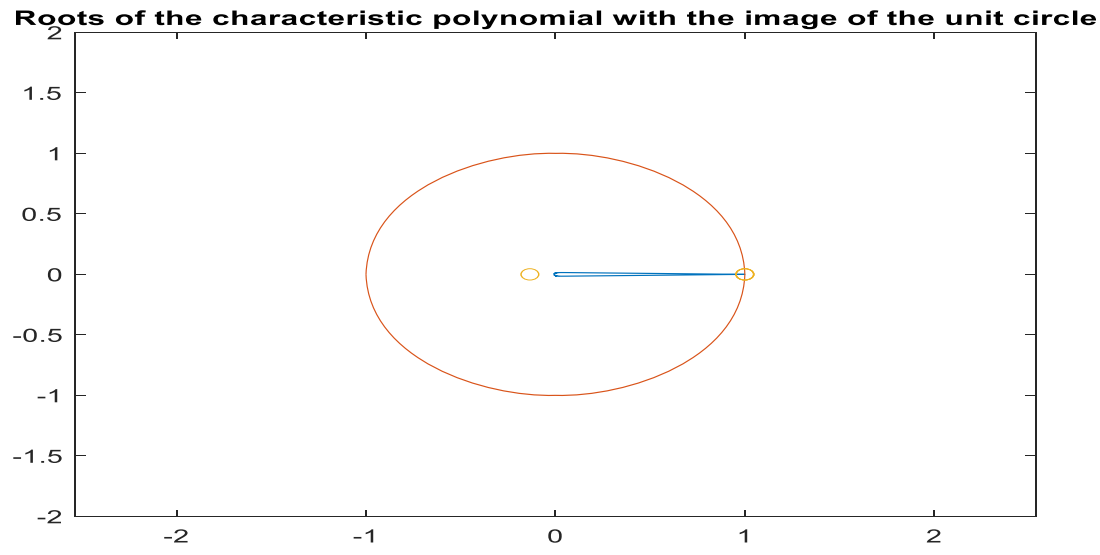


Fig. 4 COVID-19 sample stability test

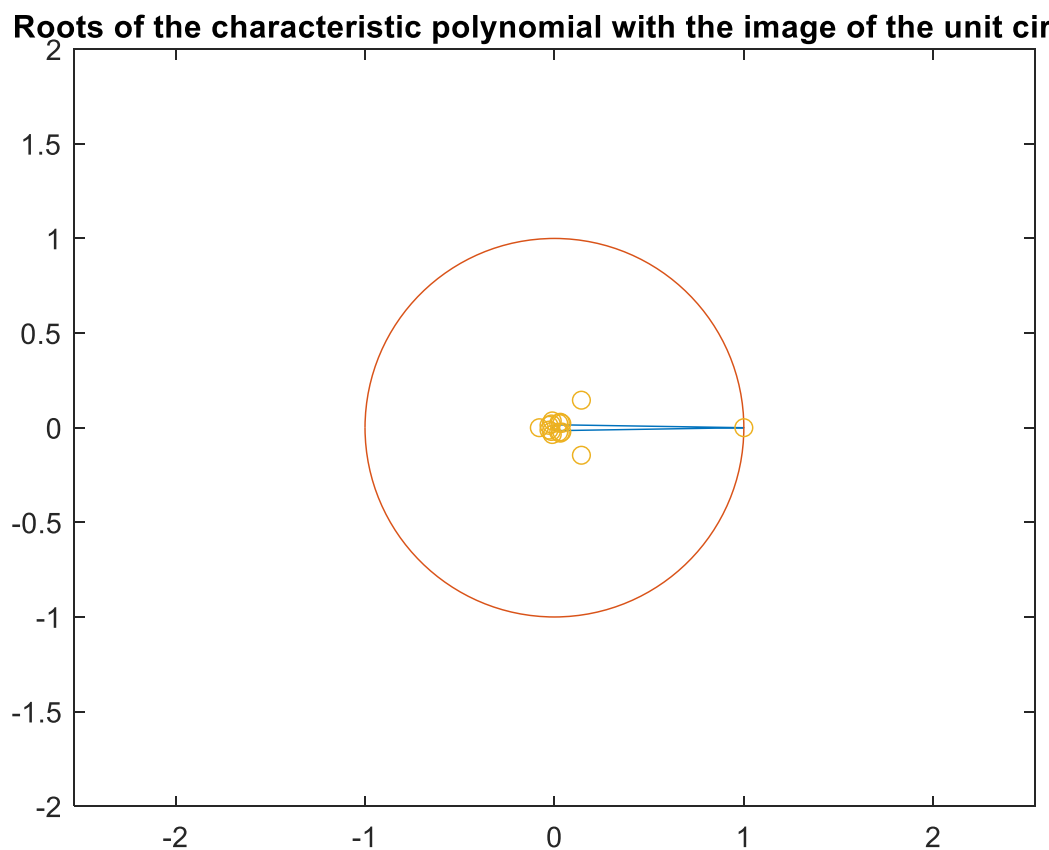

LR statistics was found significant for all samples with exception of the pre-COVID-19 sample. This highlights that the fractional integration is better fit for the full sample and the COVID-19 and the COVID-19 pandemic period sub-samples, as the fractional parameter is $d<0.5$ while the CVAR model is better fit for the pre-COVID-19 period where $d>0.5$. Both cointegration techniques alongside the parameter stability tests lend support to the existence of a persistence and stable long-run relationships among the series irrespective of the sample period considered.
The persistence and stable long-run relationships confirmed between precious metals and oil prices irrespective of the sample periods considered have enormous empirical implications for nations that are endowed with precious metals and oil. Results show that precious metals respond to shocks to oil prices either positively or negatively. Hence, precious metals are sensitive to shocks to oil prices irrespective of the economic situations. The persistence and stable long-run relationships is an indication of a direct relationship between precious metals and oil prices. An increase in oil price stimulates
Fig. 5 COVID-19 pandemic sample stability test

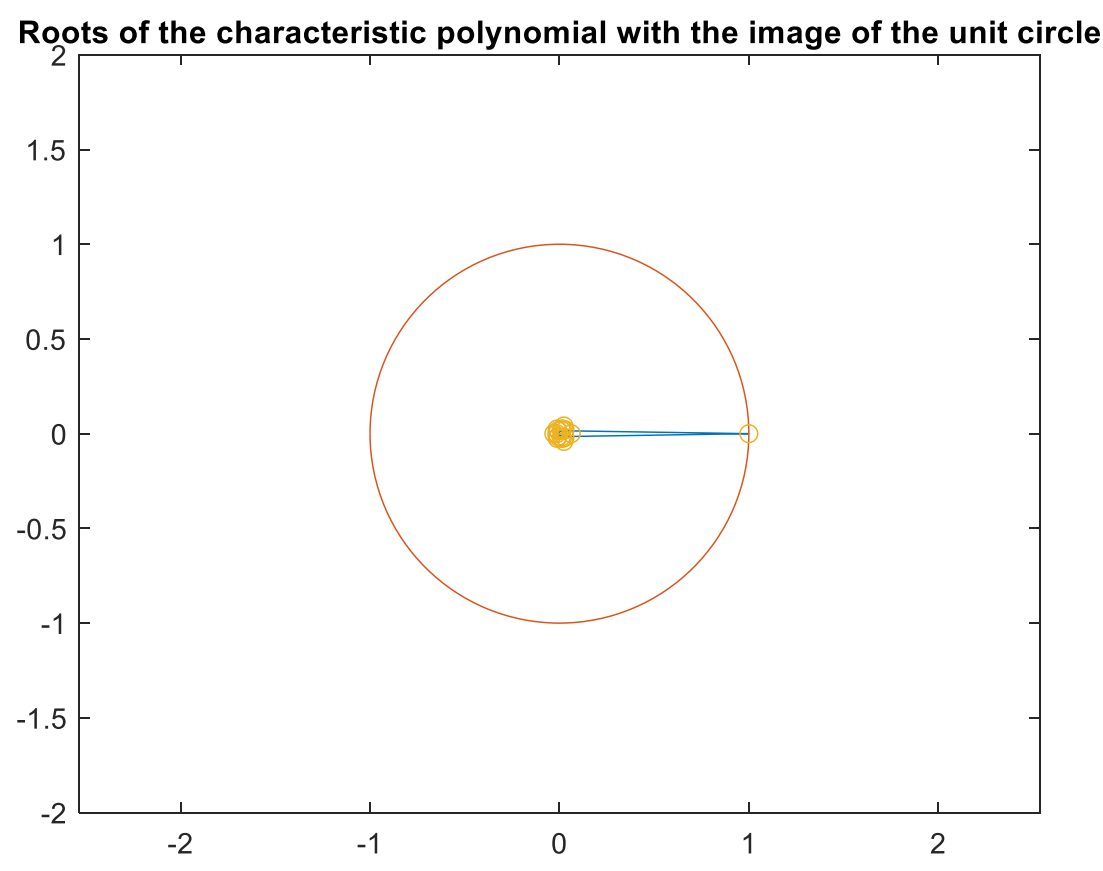


inflation. As inflation increases, precious metals become a preferred and better-fit hedge against rising inflation. Comparatively, the prices of precious metal rise as general price level begin to rise, and vice versa. This finding resonates the study of Charlot and Marimoutou (2014) for the United States.

Understanding the relationship between precious metals and oil prices is significant for decision-making process, most especially when it comes to risk, production, and portfolio management. As oil prices increases, investment in precious metals becomes beneficial in terms of high returns to investors in the long run (Jain and Ghosh 2013). This implies that investment in precious metals can make an efficient portfolio, which diversifies risk and facilitates desirable risk adjust returns (Arif et al. 2019). It is paramount to mention that the direct relationships between oil and precious metals would out behind growth in manufacturing sectors, specifically when it comes to cost of purchasing precious metals and oil (Arif et al. 2019).

Conclusively, from a policy standpoint, we believe that investors should put their ears to the ground and eyes on the variations (fluctuations) noticeable with these commodities prices in terms of pattern and trend. Governments and investors should diversify their portfolio and invest more in precious metals to minimize future shocks to oil prices and capital loss due to fluctuation in oil price changes, thus guaranteeing maximum returns for investors and increase in foreign exchanges earnings for the government. Policymakers on the other hand should enhance the share of previous metals as an asset reserve away from oil dependence. This policy should be put in place to halt domestic currency from losing its value and at the same depletion of nation foreign reserves.

Acknowledgements We appreciate the anonymous referees for their insightful comments. Any other errors are solely ours.

Author contribution Nuruddeen Usman: Responsible for study development, methodology, and empirical discussion. Seyi Akadiri: Responsible for the study development.

\section{Data availability Not applicable}

\section{Declarations}

Ethics approval Authors mentioned in the manuscript have agreed for authorship, read, and approved the manuscript and given consent for submission and subsequent publication of the manuscript.

\section{Consent to participate Note applicable}

Consent for publication Note applicable

Competing interests The authors declare no competing interests.

\section{References}

Akhtaruzzaman M, Boubaker S, Sensoy A (2021) "Financial contagion during COVID-19 crisis." Finance Res Lett 38:101604

Akhtaruzzaman M, Boubaker S, Chiah M, Zhong A (2020) COVID- 19 and oil price risk exposure. Finance research letters, 101882

Al-Awadhi AM, Alsaifi K, Al-Awadhi A, Alhammadi S (2020) Death and contagious infectious diseases: Impact of the COVID-19 virus on stock market returns. Journal of behavioral and experimental finance, 27:100326

Arif I, Khan L, Iraqi KM (2019) Relationship between oil price and white precious metals return: a new evidence from quantile-on-quantile regression. Pak J Commer Soc Sci (PJCSS) 13(2):515-528

Arouri MEH, Hammoudeh S, Lahiani A, Nguyen DK (2012) Long memory and structural breaks in modeling the return and volatility dynamics of precious metals. Q Rev Econ Finance 52(2):207-218

Ashraf BN (2020) Economic impact of government interventions during the COVID-19 pandemic: international evidence from financial markets. J Behav Exp Financ 27:100371

Bai J, Lumsdaine RL, Stock JH (1998) Testing for and dating common breaks in multivariate time series. Rev Econ Stud 65(3):395-432

Balcilar M, Usman O (2021) Exchange rate and oil price pass-through in the BRICS countries: evidence from the spillover index and rollingsample analysis. Energy 229:120666

Balcilar M, Roubaud D, Usman O, Wohar ME (2021) Moving out of the linear rut: a period-specific and regime-dependent exchange rate and oil price pass-through in the BRICS countries. Energy Econ 98: 105249

Batten JA, Ciner C, Lucey BM (2010) The macroeconomic determinants of volatility in precious metals markets. Res Policy 35(2):65-71

Baur DG, Lucey BM (2010) Is gold a hedge or a safe haven? An analysis of stocks, bonds and gold. Financ Rev 45(2):217-229

Ben Nasr A, Ajmi AN, Gupta R (2014) Modelling the volatility of the Dow Jones Islamic Market World Index using a fractionally integrated time-varying GARCH (FITVGARCH) model. Applied Financial Economics, 24(14):993-1004

Bildirici ME, Turkmen C (2015) Nonlinear causality between oil and precious metals. Res Policy 46:202-211

Cai J, Cheung Y-L, Wong MCS (2001) What moves the gold market? Journal of Futures Markets: Futures, Options, and Other Derivative Products 21(3):257-278

Caporale GM, Pittis N (1999) Unit root testing using covariates: some theory and evidence. Oxf Bull Econ Stat 61(4):583-595

Charlot P, Marimoutou V (2014) On the relationship between the prices of oil and the precious metals: revisiting with a multivariate regimeswitching decision tree. Energy Econ 44:456-467

Corbet S, Larkin C, Lucey B (2020) The contagion effects of the COVID-19 pandemic: Evidence from gold and cryptocurrencies. Finance Research Letters, 35:101554

Devpura N, Narayan PK (2020) Hourly oil price volatility: the role of COVID-19. Energy Research Letters 1(2):13683

Dickey DA, Fuller WA (1979) Distribution of the estimators for autoregressive time series with a unit root. J Am Stat Assoc 74(366a):427-431

Diebold FX, Rudebusch GD (1991) Is consumption too smooth? Long memory and the Deaton paradox. Rev Econ Stat 73:1-9

Fama EF (1965) The behavior of stock-market prices. J Bus 38(1):34 105

Gil-Alana LA, Carcel H (2020) A fractional cointegration var analysis of exchange rate dynamics. N Am J Econ Finance 51:100848

Gil-Alana LA, Monge M (2020) Crude oil prices and COVID-19: persistence of the shock. Energy Research Letters 1(1):13200

Gil-Alana L, Ave G, Gupta R (2013) Testing for persistence in South African house prices. J Real Estate Lit 21(2):293-314 
Gil-Alana LA, Chang S, Balcilar M, Aye GC, Gupta R (2015a) Persistence of precious metal prices: a fractional integration approach with structural breaks. Res Policy 44:57-64

Gil-Alana LA, Aye GC, Gupta R (2015b) Trends and cycles in historical gold and silver prices. J Int Money Financ 58:98-109

Greenspan A (1993) The Fed aims for price stability. Challenge 36(5):4 10

Jain A, Ghosh S (2013) Dynamics of global oil prices, exchange rate and precious metal prices in India. Res Policy 38(1):88-93

Ji Q, Zhang D, Zhao Y (2020) Searching for safe-haven assets during the COVID-19 pandemic. Int Rev Financ Anal 101526

Johansen S (1995) Likelihood-based inference in cointegrated vector autoregressive models. Oxford University Press on Demand

Johansen S (1996) Likelihood-based inference for cointegration of some nonstationary time series. In Time Series Models (pp. 69-100). Springer US

Johansen S, Nielsen MØ (2010) Likelihood inference for a nonstationary fractional autoregressive model. J Econ 158(1):51-66

Johansen S, Nielsen MØ (2012) Likelihood inference for a fractionally cointegrated vector autoregressive model. Econometrica 80(6): $2667-2732$

Kirkulak UB, Lkhamazhapov Z (2014) Long memory and structural breaks in the returns and volatility of gold: evidence from Turkey. Appl Econ 46(31):3777-3787

Mensi W et al (2020) Impact of COVID-19 outbreak on asymmetric multifractality of gold and oil prices. Res Policy 69:101829

Mishra AK, Rath BN, Dash AK (2020) Does the Indian financial market nosedive because of the COVID-19 outbreak, in comparison to after demonetisation and the GST? Emerg Mark Financ Trade 56(10): 2162-2180

Mugaloglu E, Polat AY, Tekin H, Dogan A (2021) Oil price shocks during the COVID-19 pandemic: evidence from United Kingdom energy stocks. Energy Research Letters 2(1):24253

Narayan PK (2020) Oil price news and COVID-19-is there any connection?, 1. Energy Research Letters, 1(1):13176
Narayan PK, Liu R (2015) A unit root model for trending time-series energy variables. Energy Econ 50:391-402

Morten Ørregaard Nielsen \& Michal Ksawery Popiel, 2018. "A Matlab program and user's guide for the fractionally cointegrated var model," Working Paper 1330, Economics Department, Queen's University.

Phan DHB, Narayan PK (2020) Country responses and the reaction of the stock market to COVID-19 - a preliminary exposition. Emerg Mark Financ Trade 56(10):2138-2150

Phillips PCB, Perron P (1988) Testing for a unit root in time series regression. Biometrika 75(2):335-346

Robinson PM (1994) Semiparametric analysis of long-memory time series. The Annals of Statistics, 515-539

Robinson PM (1995) Gaussian semiparametric estimation of long range dependence. Ann Stat 23(5):1630-1661

Salisu AA, Sikiru AA (2020) Pandemics and the Asia-Pacific islamic stocks, 1. Asian Economics Letters, 1(1):17413

Salisu AA, Vo XV (2020) Predicting stock returns in the presence of COVID-19 pandemic: the role of health news. Int Rev Financ Anal 71:101546

Salisu AA, Ebuh GU, Usman N (2020) Revisiting oil-stock nexus during COVID-19 pandemic: some preliminary results. Int Rev Econ Financ 69:280-294

Sowell F (1992) Maximum likelihood estimation of stationary univariate fractionally integrated time series models. J Econ 53(1-3):165-188

Tang K, Xiong W (2012) Index investment and the financialization of commodities. Financ Anal J 68(6):54-74

Topcu M, Gulal OS (2020) The impact of COVID-19 on emerging stock markets. Financ Res Lett 36:101691

Zhang, Dayong, Min Hu, and Qiang Ji. "Financial markets under the global pandemic of COVID-19.” Finance Research Letters (2020): 101528

Publisher's note Springer Nature remains neutral with regard to jurisdictional claims in published maps and institutional affiliations. 